\title{
Electrocatalytic Oxidation of Paraacetylaminophenol on a Graphite Electrode Modified with Iron Oxides
}

\author{
Abdelhakim Benchettara, ${ }^{a}$ Mohamed Sidoumou, ${ }^{b}$ Razika Mehdaoui, ${ }^{b, *}$ \\ Abdelkader Zarrouk ${ }^{c}$ and Abdelkader Benchettara ${ }^{a, d}$ \\ ${ }^{a}$ Laboratory of Electrochemistry-Corrosion, Metallurgy and Inorganic Chemistry- \\ Fac. Chemistry USTHB- P.O. Box 32, El Alia Bab Ezzouar, Algiers 16111, Algeria \\ ${ }^{b}$ Laboratory of LCSN-BioM, Saâd Dahlab of Blida-1 University, P.O. Box.270, \\ Route de Soumaa 09000, Blida, Algeria \\ ${ }^{c}$ LCAE-URAC 18, Faculty of Science, First Mohammed University, \\ P.O. Box 717, 60 000, Oujda, Morocco \\ ${ }^{d}$ National Preparatory School for Engineering Studies (ENPEI), \\ P.O. Box 05,Rouiba, Algiers, Algeria
}

Received September 11, 2017; accepted May 05, 2018

\begin{abstract}
The goal of this study was to propose an electrochemical sensor for Paracetamol determination. To reach this objective, a graphite electrode (GE) was modified with iron oxides, and it was tested in an alkaline aqueous solution, in order to appreciate its electrocatalytic properties towards paraacetylaminophenol anodic oxidation. The graphite electrode modification was performed, in a first step, by potentiostatic deposition of an iron film at $-1 \mathrm{~V} / \mathrm{SCE}$, in an aqueous solution of $0.04 \mathrm{M} \mathrm{Fe}\left(\mathrm{NO}_{3}\right)_{3}+$ $0.15 \mathrm{M} \mathrm{KNO}_{3}$, followed, in a second step, by cyclic voltammetry in an aqueous solution of $0.1 \mathrm{M}$ sodium hydroxide, at $25^{\circ} \mathrm{C}$. The modified electrode was characterized by means of scanning electron microscope coupled to an EDAX X-Ray micro-analyser. Paraacetylaminophenol determination by means of this novel sensor was instantaneous in an alkaline solution. The performance of this sensor was obtained in the concentration range from $13 \mathrm{ppm}$ to $320 \mathrm{ppm}$, with a sensitivity of $1.6 \times 10^{4} \mu \mathrm{A} \mathrm{mol}^{-1} \mathrm{~L}$.
\end{abstract}

Keywords: Electrocatalytic oxidation, iron oxides, paraacetylaminophenol, cyclic voltammetry, potentiostatic polarization, electrochemical sensor.

\section{Introduction}

Paracetamol, acetaminophen or paraacetylaminophenol are the names of a widely used drug that is the active ingredient of many medicinal specialties; it carries out phenol and amide functions. It is recommended for the symptomatic treatment of fever and low to moderate pain. The development of a simple and affordable

\footnotetext{
* Corresponding author. E-mail address: v.hambategomdje@usms.ma
} 
rapid dosing technique of this medication is a necessity. Electrodes electrochemical modification to manufacture sensors that meet the requirements of the above mentioned dosing is a new technique widely used by several authors during the last years [1-2]. The modified electrodes have, in addition to the electrocatalytic detection, many other uses, such as fuel cells [3], electrochromism [4-6], solar cells [7-9] and others. The numerous graphite properties and advantages, such as good electrical conductivity, wide abundance and low cost, make it preferable among the materials of choice as substrates in the manufacture of high performance electrochemical sensors [10]. The literature on the manufacture of such electrochemical sensors mentions many electrocatalytic materials, such as conductive polymers [11-13], complexes [14] and transition metal oxides; among the latter, there are those based on copper [15-16], cobalt [17-18], nickel [19-22], zinc [23-24], manganese [25], iron [2628], or alloys of these metals [29-32]. The presence of the oxidized form of the foregoing inorganic materials in the electrochemical sensor provides an intense electrocatalytic performance [33] capable of oxidizing several organic substances, such as amino acids [34-37], sugars [38-39] and alcohols [40-42]. Several studies have developed coated graphite electrochemical-based sensors from different materials capable to dose paracetamol [43-44].

In this work, a graphite electrode has been coated with an iron oxide, and has been used as an electrochemical sensor for paracetamol electrocatalytic oxidation, in an alkaline medium. This sensor has good reproducibility, very short response time (instantly) and a detection limit of the ppm order.

\section{Experimental \\ Materials and reagents}

Iron (III), nitrate $\left(\mathrm{Fe}\left(\mathrm{NO}_{3}\right)_{3}\right)$, potassium nitrate $\left(\mathrm{KNO}_{3}\right)$ and sodium hydroxide $(\mathrm{NaOH})$ used in this work were of analytical grade, and were purchased from Sigma Aldrich manufacturer. These reagents were used without further purification. The paraacetylaminophenol solution was prepared from a drug manufactured by Merinal laboratories. All solutions were prepared with distilled water, without removing dissolved oxygen. Electrochemical studies were realised in a three-electrode cell powered by a Versastat 3 model Potentiostat/Galvanostat, controlled by Versa-Studio software. Along this work, we have used a $\mathrm{Hg} / \mathrm{Hg}_{2} \mathrm{Cl}_{2}$ /saturated $\mathrm{KCl}$ aqueous solution as reference electrode (SCE) (Radiometer, XR 110), a filiform platinum electrode (Radiometer, XM 110) as auxiliary electrode, and a disk shaped graphite microelectrode of $6 \mathrm{~mm}$ in diameter, as working electrode. All studies were carried out at $25 \pm 0.2{ }^{\circ} \mathrm{C}$.

\section{Electrode modification}

GE was polished to a mirror finish before each modification by means of a polishing machine (Mercapol B), with $0.3 \mu \mathrm{m}$ alumina, and rinsed several times with distilled water. Metallic iron deposition on the graphite electrode was performed by potentiostatic cathodic reduction of an aqueous slurry of $0.04 \mathrm{M}$ $\mathrm{Fe}\left(\mathrm{NO}_{3}\right)_{3}$ and $0.15 \mathrm{M} \quad \mathrm{KNO}_{3}$. This reduction was achieved with 
chronoamperometry method, by applying a potential of $-1 \mathrm{~V}$, for $100 \mathrm{~s}$. After this, the electrode was removed from the ferric slurry, thoroughly washed with distilled water, and transferred into a bath containing an aqueous solution of 0.1 $\mathrm{M} \mathrm{NaOH}$; several potential scans were applied from $-1.6 \mathrm{~V}$ to $+0.6 \mathrm{~V}$, at a scan rate of $0.05 \mathrm{~V} . \mathrm{s}^{-1}$, in a cyclic voltammetry regime, to oxidize the iron film previously deposited on the graphite electrode.

It is important to visualize and analyze the structure and the morphology of the modified electrode. This characterization was realized by a SEM Microscope (type Quanta 400 MK2, FEI brand), coupled to an "EDAX" X-ray microanalyzer, and equipped with a secondary electron detector (SED), a backscattered electron detector (BSED), an "EDAX" X-ray detector and two video screens with "Quanta, EDAX Genesis GSR" software.

\section{Results and discussion}

\section{Surface characterisation}

Electrochemical characterisation

Fig. 1 shows the chronoamperogram recorded during the potentiostatic polarization at $-1 \mathrm{~V}$, of the graphite interface/0.04 $\mathrm{M} \mathrm{Fe}\left(\mathrm{NO}_{3}\right)_{3}$ and $0.15 \mathrm{M}$ $\mathrm{KNO}_{3}$.

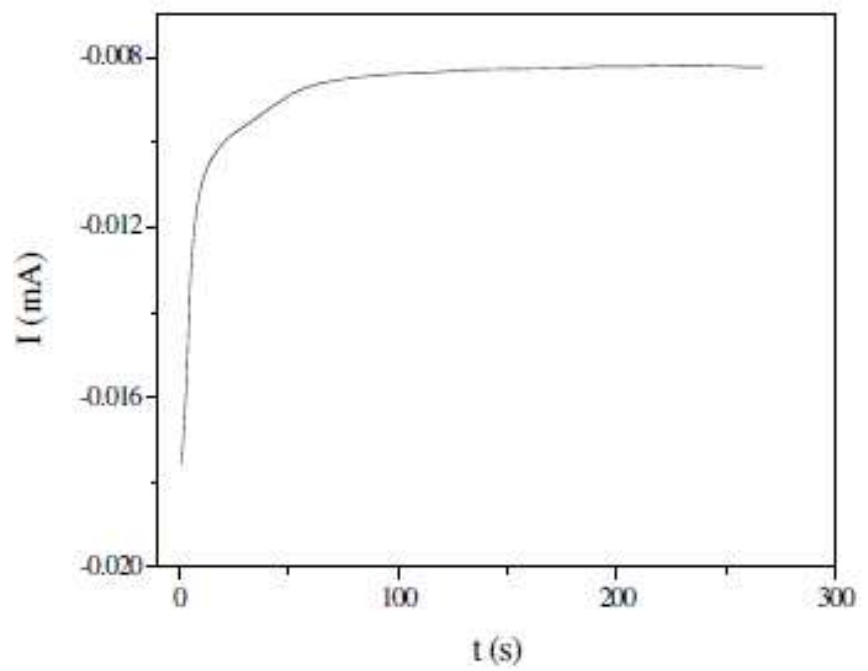

Figure 1. Chronoamperogram of metallic iron electrodeposition on the graphite electrode, at $-1 \mathrm{~V}$, in an aqueous slurry of $0.04 \mathrm{M} \mathrm{Fe}\left(\mathrm{NO}_{3}\right)_{3}$ and $0.15 \mathrm{M} \mathrm{KNO}_{3}$, at $25^{\circ} \mathrm{C}$.

It consists of a sharp branch attributed to the electric double layer discharge and to two-time intensity characteristics which can be interpreted by the following mechanism:

$$
\begin{gathered}
\mathrm{Fe}^{3+}{ }_{a q}+e \rightleftharpoons \mathrm{Fe}^{2+}{ }_{a q} \\
\mathrm{Fe}^{2+}{ }_{a q}+2 e \rightleftharpoons \mathrm{Fe}_{a d s}
\end{gathered}
$$


Fig. 2 shows the curve of the first derivative, with respect to time, of the previous chronoamperogram.

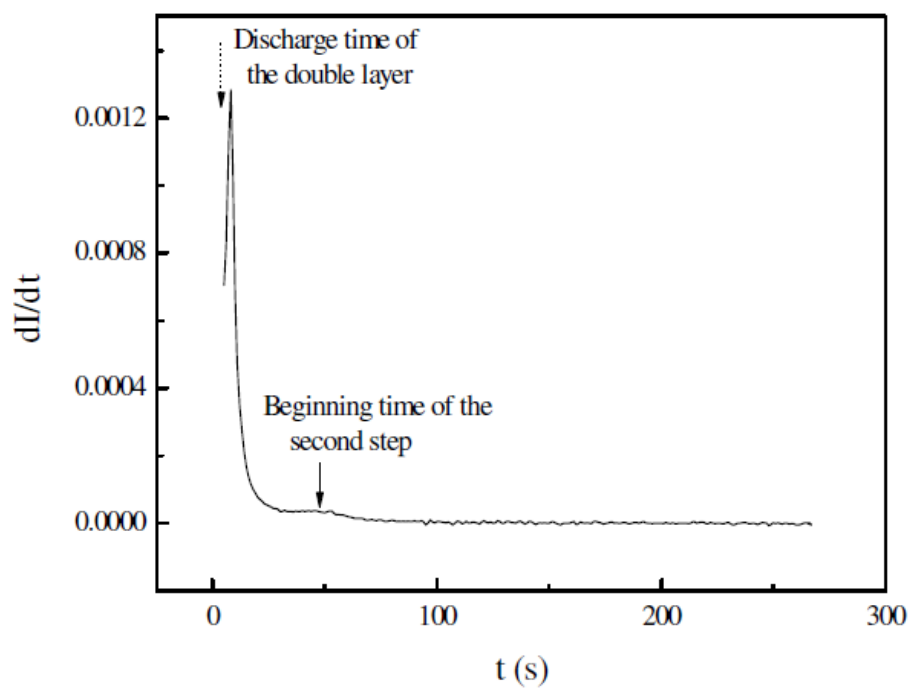

Figure 2. Graph of the first derivative, with respect to time, of the previous chronoamperogram.

From Fig. 2, one distinguishes a steep peak located at $\mathrm{t}=4 \mathrm{~s}$, and another peak, more spread out, corresponding to the beginning of the second reduction reaction, which took place between $t_{2}=49 \mathrm{~s}$ and $t_{3}=300 \mathrm{~s}$ times. The integration of the chronoamperogram between $t_{1}=4 \mathrm{~s}$ and $t_{3}=300 \mathrm{~s}$ times gives an electricity quantity $\left(\mathrm{Q}=500 \mu \mathrm{C} \mathrm{cm}^{-2}\right)$, which corresponds to a recovery rate $(\theta=$ $79.6 \%)$ of the graphite electrode surface. Indeed, a simple calculation based on a Fe atomic radius of $156 \mathrm{pm}$ shows that, for a disc-shaped electrode of $3 \mathrm{~mm}$ in radius, the maximum amount of electricity corresponding to a monolayer is 628 $\mu \mathrm{C} \mathrm{cm}^{-2}$.

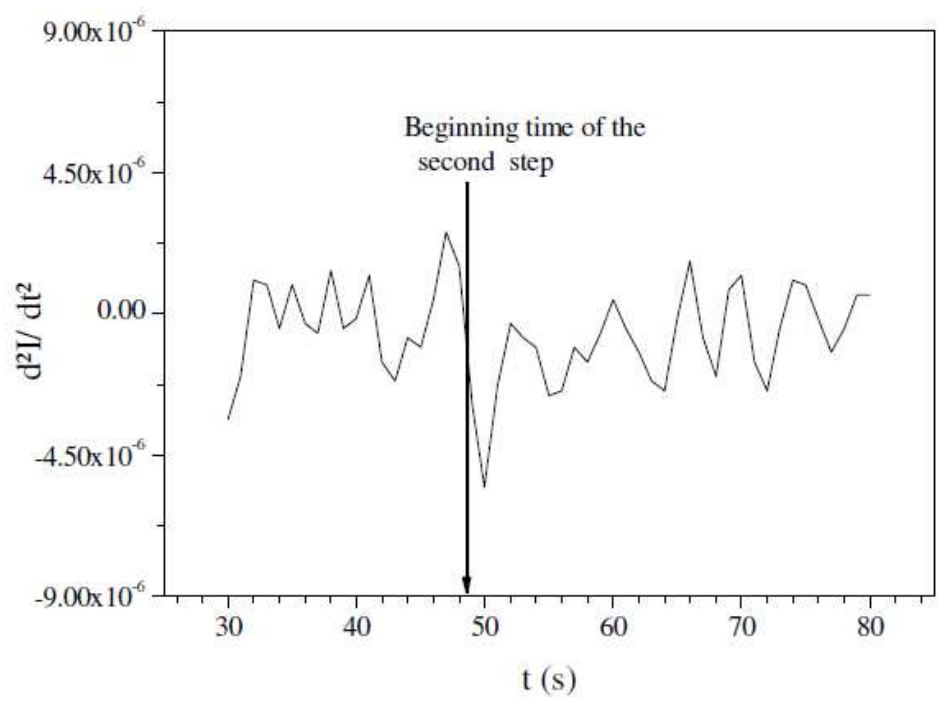

Figure 3. Graph of the second derivative of the previous chronoamperogram, with respect to time. 
Fig. 3 represents the second derivative of the chronoamperogram versus time; it shows the existence of an inflection point at $\mathrm{t}_{2}=49 \mathrm{~s}$. This change in concavity of the chronoamperogram is an indication that a second reduction reaction occurred in the cathodic process.

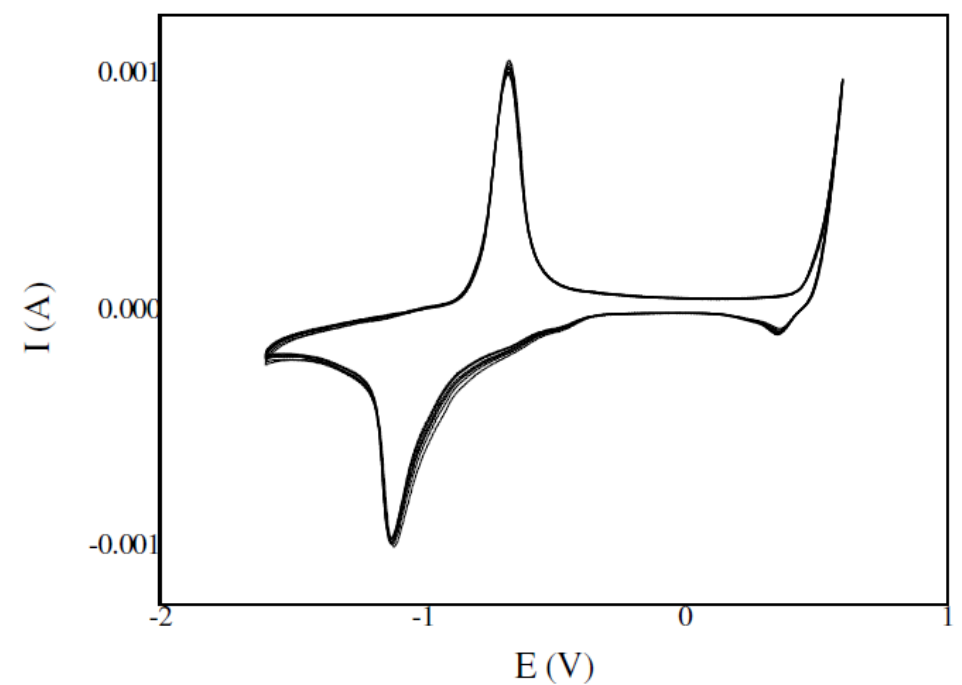

Figure 4. Voltammograms of $\mathrm{Fe}(\mathrm{OH})_{3, \mathrm{~s}} / \mathrm{Fe}(\mathrm{OH})_{2, \mathrm{~s}}$ on $\mathrm{Fe} / \mathrm{C} / 0.1 \mathrm{M} \mathrm{NaOH}$ electrode, at $100 \mathrm{mVs}^{-1}$, at $25^{\circ} \mathrm{C}$.

Fig. 4 represents 10 consecutive cyclic voltammograms recorded at the Fe/graphite electrode/ $0.1 \mathrm{M} \mathrm{NaOH}$ interface; it is important to note that the steady state of the electrode was achieved at the first cycle; the almost perfect overlapping of the consecutive voltammograms attests to the high stability of the modified electrode. Two well-defined peaks located around $-0.690 \mathrm{~V}$ and -1.088 $\mathrm{V}$ were attributed to the reversible $\mathrm{Fe}(\mathrm{OH})_{3} / \mathrm{Fe}(\mathrm{OH})_{2}$ system. The formation of iron oxides on the electrode surface can be interpreted by the following mechanism:

- In a first step, during OCP measurement of Fe/C/0.1 M NaOH, iron adatoms are chemically oxidized by dissolved oxygen, according to the following equation:

$$
\mathrm{Fe}_{\text {ads }}+{ }^{1 / 2} \mathrm{O}_{2, a q}+\mathrm{H}_{2} \mathrm{O}_{l} \rightleftharpoons \mathrm{Fe}(\mathrm{OH})_{2, s}
$$

- In a second step, during cyclic voltammetry polarization, in the anodic direction, from $-1.6 \mathrm{~V}$ to $0.6 \mathrm{~V}$, the reversible electron transfer reaction occurs, as in the following equation:

$$
\mathrm{Fe}(\mathrm{OH})_{2, s}+\mathrm{OH}^{-}{ }_{a q} \rightleftharpoons \mathrm{Fe}(\mathrm{OH})_{3, s}+e
$$

Fig. (5a) shows the anodic and cathodic peak currents of iron oxides increase, by increasing the potential sweep rate in the range from 10 to $90 \mathrm{mV} \mathrm{s}^{-1}$, in a $0.1 \mathrm{M}$ $\mathrm{NaOH}$ solution. The peak potentials shifted to more positive values in the anodic direction, and to more negative values in the cathodic direction. These observations are in good accordance with the oxide accumulation on the surface electrode. Figs. (5b and 5c), respectively, show that anodic and cathodic peak 
currents are directly proportional to the scan rate potential, confirming that iron oxides adsorbed onto the surface electrode.

Another point observed in Fig. ( 5 a) is that the peak-to-peak separation, even at slow potential sweep rates, has a finite value. This deviation of the redox process from the ideal surface redox process, appearing even at low scan rates, may be attributed to the limitations associated to charge propagation in the film, chemical interaction between the ions and the modifier film, polarizability of the ions influencing its penetration in or out of the film, or to non-equivalent sites in the film.

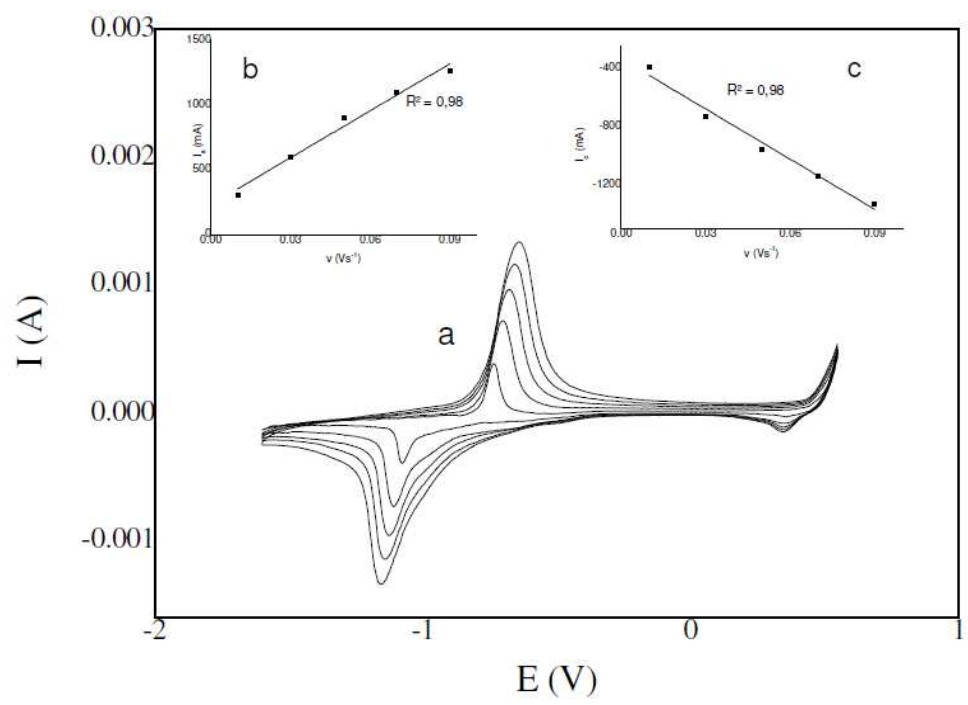

Figure 5. (a) Cyclic voltammograms of iron oxides modified graphite electrode in

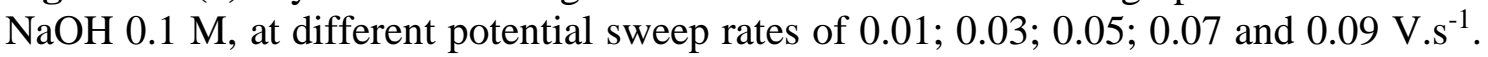
Inset: variation of (b) anodic and (c) cathodic current intensity with scan rate potential.

\section{SEM analysis}

The surface of the graphite electrode modified with an iron oxide was analysed by scanning electron microscopy (SEM). Fig. 6a shows the SEM image for the modified electrode.
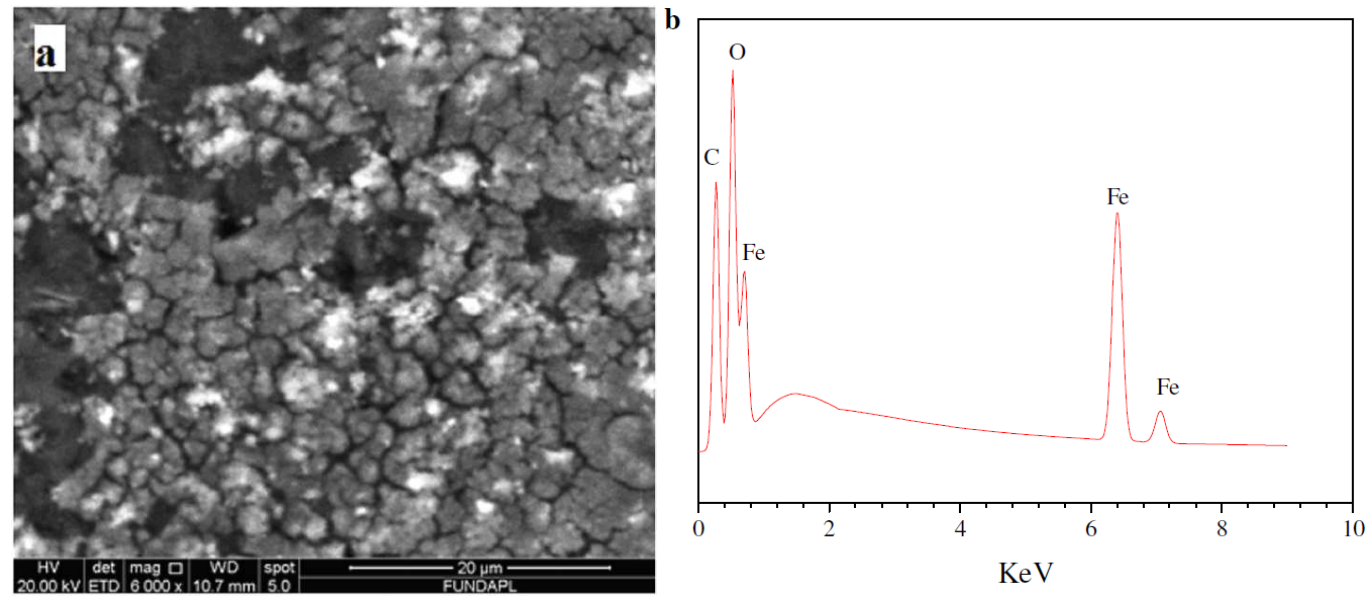

Figure 6. SEM micrograph (a) and EDS analysis (b) of the modified electrode. 
The examination of this figure allowed us to observe the existence of a light contrast. This was due to the more massive iron, while the dark section was due to the graphite electrode. The SEM image reveals the formation of large crystallites. The dark lines show the grain boundaries.

The presence of both iron and oxygen in the modified electrode was revealed by Energy Dispersive Spectroscopy analysis (Fig.6b). A typical EDS spectrum indicates that the modified electrode contains carbon, oxygen, and iron. Carbon presence in the modified electrode was due to the graphite electrode initially used.

The average composition of the modified electrode can be quantitatively estimated. Around $72 \% \mathrm{O} / 28 \% \mathrm{Fe}$ were found. In the future, further investigations will be made. For example, by X-ray Diffraction (XRD), to determine the crystalline structure of the crystallites.

\section{Paracetamol electro-oxidation}

Fig. 7 includes paracetamol oxidation voltammograms on the modified graphite electrode with iron oxides in $0.1 \mathrm{M} \mathrm{NaOH}$. This figure shows an anodic peak located at about $50 \mathrm{mV}$, which increases with the increase in Paracetamol concentration in the electrochemical cell. This increase is followed by a decrease in the intensity of the corresponding cathodic peak.

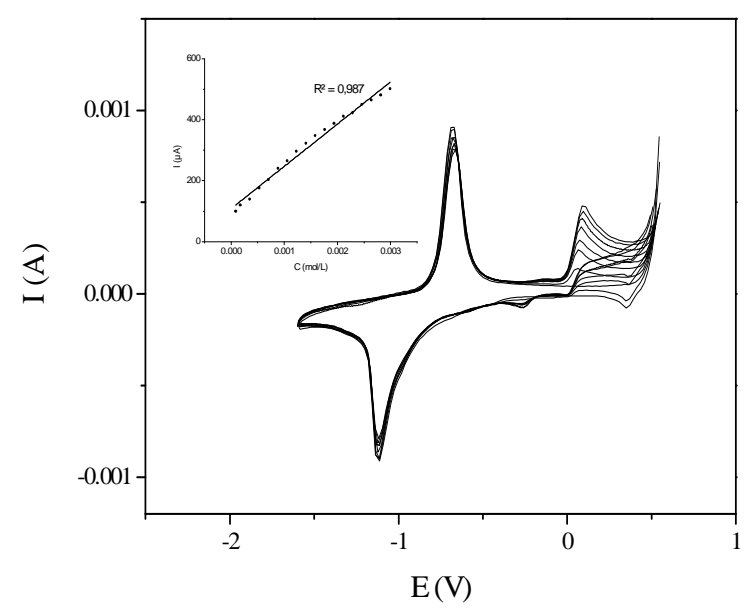

Figure 7. Voltamperograms recorded during paracetamol oxidation on graphite modified with iron oxides, in $0.1 \mathrm{M} \mathrm{NaOH}$, at $0.1 \mathrm{~V} \mathrm{~s}^{-1}$, at $25{ }^{\circ} \mathrm{C}$. Inset: calibration curve for paracetamol oxidation in the range from $88.6 \mu \mathrm{mol} / \mathrm{L}$ to $3.0 \mathrm{mmol} / \mathrm{L}$ (see Table 1).

The following mechanism interprets well the oxidation process of paraacetylaminophenol, in an alkaline medium.

$$
\begin{aligned}
& 3 \mathrm{O}_{2, \text { ads }}+4 \mathrm{Fe}(\mathrm{OH})_{3, s} \rightarrow 4 \mathrm{FeO}_{4, \text { ads }}^{2-}+8 \mathrm{H}_{a q}^{+}+2 \mathrm{H}_{2} \mathrm{O}_{l} \\
& 4 \mathrm{FeO} \mathrm{O}_{4, \text { ads }}^{2-}+\text { Paracetamol } \rightarrow 4 \mathrm{Fe}(\mathrm{OH})_{3, s}+\text { Oxidtion product }
\end{aligned}
$$


Table1. Comparison of results for the iron oxides/G sensor with those found in the literature, for paraacetylaminophenol detection in an alkaline medium.

\begin{tabular}{lccc}
\hline Electrode & $\begin{array}{c}\text { Linear range } \\
\left(\mu \text { mol. } \mathrm{L}^{-1}\right)\end{array}$ & $\begin{array}{c}\text { Limit of detection } \\
\left(\mu \text { mol. } \mathrm{L}^{-1}\right)\end{array}$ & Ref. \\
\hline Microfluidic paper-based & - & 25.0 & {$[45]$} \\
screen-printed electrodes & 2.5 to 1000.0 & 0.1 & {$[46]$} \\
Screen-printed carbon electrodes & Up to 0.2 & 13.0 & {$[47]$} \\
GO/GCE & 0.05 to 1 & $4.910^{-2}$ & {$[48]$} \\
Iron oxides/G & 88.6 to 300.0 & 13.0 & This work \\
\hline
\end{tabular}

\section{Conclusion}

The development of a new graphite electrode modified with iron oxides allowed us to successfully dose commercial paraacetylaminophenol in an alkaline solution of $\mathrm{pH}$ 12. We suggest $\mathrm{FeO}_{4}{ }^{2-}$ ads/C as a mediator for paraacetylaminophenol catalytic oxidation. In addition, the proposed mechanism explains well the constancy of anodic and cathodic peaks of the $\mathrm{Fe}(\mathrm{OH})_{3} / \mathrm{Fe}$ $(\mathrm{OH})_{2}$ couple. This electrode showed good reproducibility and very short response time. Paraacetylaminophenol dosage was performed with a detection limit of $13.0 \mu \mathrm{mol} / \mathrm{L}$, and a sensitivity of $1.6 \times 10^{4} \mu \mathrm{A} \mathrm{mol}^{-1} \mathrm{~L}$.

\section{References}

1. Hanafi I, Daud AR, Radiman S. Port Electrochim Acta. 2017;35:1-12.

2. Karim-Nezhad G, Pashazadeh S. Port Electrochim Acta. 2016;34:85-95.

3. Bouabdalaoui L, Legrand L, Féron D, et al. Electrochem Comm. 2013;28:14.

4. Karuppasamy A. Appl Surf Sci. 2013;282:77-83.

5. Kimura G, Yamada K. Synth Met. 2009;159:914-918.

6. Ribeiro AS, da Silva AU, Navarro M, et al. Electrochim Acta. 2006;51:48924896.

7. Guo S-q, Sun M-q, Gao G-d, et al. Electrochim Acta. 2015;176:1165-1170.

8. Ke C-R, Chang C-C, Ting J-M. J Power Sources. 2015;284:489-496.

9. Sebastián D, Baglio V, Girolamo M, et al. J Power Sources. 2014;250:242249.

10. Velichkova F, Julcour-Lebigue C, Koumanova B,et al. J Environ Chem Eng. 2013;1:1214-1222.

11. Liu A-L, Zhang S-B, Chen W, et al. Biosens Bioelectron. 2008;23:14881495.

12. Radhia MM, Al-Mullab EA. Port Electrochim Acta. 2016;34:97-103.

13. Yao Y-L, Shiu K-K. Electrochim Acta. 2007;53:278-284.

14. Jin G, Du S, Hu X. Talanta. 2009;80:858-863.

15. Gu Y, Yan X, Liu W, et al. Electrochim Acta. 2015;152:108-116.

16. Qiao Y, Xu T, Zhang Y, et al. Sens Actuat B-Chem. 2015;220:1064-1069.

17. Fan LF, Wu XQ, Guo MD, et al. Electrochim Acta. 2007;52:3654-3659.

18. Salimi A, Hallaj R, Soltanian S. Biophys Chem. 2007;130:122-131.

19. Bing L, Huatang Y, Yunshi Z, et al. J Power Sources. 1999;79:277-280. 
20. Danaee I, Jafarian M, Forouzandeh F, et al. Electrochim Acta. 2008;53: 6602-6609.

21. Liu S, Yu B, Zhang T. Electrochim Acta. 2013;102:104-107.

22. Shamsipur M, Najafi M, Hosseini M-RM. Bioelectrochem. 2010;77:120-124.

23. Hatamie A, Echresh A, Zargar B, et al. Electrochim Acta. 2015;174:12611267.

24. Jayaraman VK, Álvarez AM, Amador MDLLO. Mater Lett. 2015;157:169171.

25. El-Refaei SM, Awad M, El-Anadouli B, et al. Electrochim Acta. 2013;92: 460-467.

26. Bhakta AK, Mascarenhas RJ, D'Souza OJ, et al. Mater Sci Eng C. 2015;57: 328-337.

27. Dey N, Devasena T. Sens Lett. 2017;15:617-631.

28. Mirzaei A, Hashemi B, Janghorban K. J Mater Sci-Mater El. 2016;27:31093144.

29. Liu Y, Xu L. Sensors. 2007;7:2446-2457.

30. Pissinis D, Sereno L, Marioli J. J Electroanal Chem. 2013;694:23-29.

31. Tominaga M, Taema Y, Taniguchi I. J Electroanal Chem. 2008;624:1-8.

32. Wang L, Lu X, Ye Y, et al. Electrochim Acta. 2013;114:484-493.

33. Chen Z, Nai J, Ma H, et al. Electrochim Acta. 2014;116:258-262.

34. Beitollahi H, Taher MA, Hosseini A. Measurement. 2014;51:156-163.

35. Benchettara A, Benchettara A. Russ J Electrochem. 2015;51:881-885.

36. Prabakar SR, Narayanan SS. J Electroanal Chem. 2008;617:111-120.

37. Tabeshnia M, Rashvandavei M, Amini R, et al. J Electroanal Chem. 2010;647:181-186.

38. Hathoot A, Yousef U, Shatla A, et al. Electrochim Acta. 2012;85:531-537.

39. Li J, Lin X. Biosens Bioelectron. 2007;22:2898-2905.

40. Benchettara A. J Fundam Appl Sci. 2014;6:187-196.

41. Danaee I, Jafarian M, Mirzapoor A, et al. Electrochim Acta. 2010;55:20932100.

42. Tominaga M, Shimazoe T, Nagashima M, et al. Electrochem Comm. 2005;7:189-193.

43. Mao A, Li H, Jin D, et al. Talanta. 2015;144:252-257.

44. Teng Y, Fan L, Dai Y, et al. Biosens Bioelectron. 2015;71:137-142.

45. Shiroma LY, Santhiago M, Gobbi AL, et al. Anal Chim Acta. 2012;725:4450.

46. Fanjul-Bolado P, Lamas-Ardisana PJ, Hernández-Santos D, et al. Anal Chim Acta. 2009;638:133-138.

47. Markas A. Analyst. 1994;119:2431-2437.

48. Zidan M, Zawawi RM, Erhayem M, et al. Int J Electrochem Sci. 2014;9: 7605-7613. 